\title{
ВПЛИВ ПРОБІОТИЧНО-ВІТАМІННО-МІНЕРАЛЬНОГО КОМПЛЕКСУ НА ІМУНОЛОГІЧНІ ПАРАМЕТРИ ПРИ ОСТЕОАРТРОЗІ НА ТЛІ ЕКСКРЕТОРНОЇ ГІПОФУНКЦІЇ ПІДШЛУНКОВОї ЗАЛОЗИ
}

\author{
๑л. С. Бабінець, І. М. Галабіцька
}

Тернопільський національний медичний університет імені І. Я. Горбачевського МОЗ України

РЕзЮМЕ. При поєднанні первинного остеартрозу та панкреатогенної екскреторної недостатності підшлункової залози у пацієнтів розвиваються зміни імунологічного статусу.

Мета - дослідити ефективність впливу додаткового призначення до комплексної терапії пацієнтів із первинним остеартрозом із панкреатогенною екзокринною недостатністю підшлункової залози пробіотично-вітамінномінерального комплексу Біон 3 на корекцію порушень імунного статусу.

Матеріал і методи. О6стежено 67 пацієнтів із первинним остеоартрозом у поєднанні з панкреатогенною екзокринною недостатністю підшлункової залози. Імунний статус пацієнтів оцінювали за рівнями CD3, CD22, CD4 i CD8, CD16, Ig M, G, А та активністю комплементу. Пацієнтів було поділено на дві групи: 1-а група отримувала протокольне лікування, 2-а група додатково до протокольного лікування отримувала пробіотично-вітамінно-мінеральний комплекс Біон 3.

Результати й обговорення. У досліджуваних пацієнтів виявлено наявність вторинної імунної недостатності за відносним супресорним варіантом на тлі зростання рівнів усіх досліджуваних класів імуноглобулінів, а також зниження неспецифічної резистентності за рівнем активності комплементу. Після комплексного лікування імунологічний статус пацієнтів статистично значимо покращився у обох групах, проте у 2-й групі лікувальний ефект був вагомішим $(p<0,05)$.

Висновок. Використання у комплексному лікуванні хворих на первинний остеоартроз у поєднанні із панкреатогенною екзокринною недостатністю підшлункової залози пробіотично-вітамінно-мінерального комплексу Біон 3 за схемою по 1 таблетці один раз на добу протягом 6 тижнів сприяє нормалізації показників імунного статуcy $(p<0,05)$.

КлючовІ СлОВА: первинний остеоартроз; екскреторна недостатність підшлункової залози; імунний статус; пробіотично-вітамінно-мінеральний комплекс.

Вступ. При прогресуванні як первинного остеоартрозу (ПОА), так і панкреатогенної гіпофункції підшлункової залози (ПЗ) унаслідок супутнього хронічного панкреатиту (ХП), стеатопанкреатозу або вікових змін при старінні виникають зміни імунологічної реактивності організму. Внаслідок цього спостерігається пригнічення активності клітинної ланки імунітету та стимуляція гуморальних факторів імуногенезу. Часто притаманна вторинна супресія клітинного імунітету. Зростання показників циркулюючих імунних комплексів при одночасному зменшенні Т-хелперів, зміни імунорегуляторного індексу вказують на імунологічний дисбаланс у хворих. Підвищений рівень TNF- $\alpha$ призводить до високого рівня системних реакцій, пов'язаних із запаленням та активацією зірчастих клітин, що, поряд зі значним підвищенням рівня TGF- $\beta$, вказує на прогресування дегенеративних процесів в уражених суглобах, а також на активне формування фіброзу ПЗ. Порушення імунного статусу у пацієнтів 3 ПОА на тлі зовнішньосекреторної недостатності ПЗ $є$ спільною патогенетичною ланкою цих коморбідних явищ, що потребує поглибленого вивчення і розробки методів корекції [1-3].

Мета - дослідити ефективність впливу додаткового призначення до комплексної терапії пацієнтів із первинним остеартрозом із панкреатогенною екзокринною недостатністю підшлункової залози пробіотично-вітамінно-мінерального комплексу Біон 3 на корекцію порушень імунного статусу.

Матеріал і методи дослідження. Обстежено 67 пацієнтів з ПОА у поєднанні із ХП у фазі стійкої або нестійкої ремісії віком від 25 до 74 років (32 чоловіки і 35 жінок). Контрольну групу складали 30 здорових людей, зіставних за віком і статтю.

Імунний статус Хворих на ПОА з ХП оцінювали за такими показниками імунітету: кількість загальної популяції CD3, CD22, CD4 і CD8, CD16, які визначали у цитотоксичному тесті з використанням моноклональних антитіл цих класів імуноферментним методом за рівнем експресії мембранних антигенів. Функціональну активність В-лімфоцитів оцінювали за концентрацією сироваткових Ig основних класів (M, G, A), які визначали методом радіальної імунодифузії за G. Mancini, принцип якого грунтується на взаємодії антигену досліджуваної сироватки і антитіла (антисироватки до Ig). Активність системи комплементу визначали за гемолітичним тестом СН50 за 50,0 \% гемолізом.

Хворих поділили на дві групи: 1-а (33 пацієнти) отримувала протокольну схему лікування. 
Огляди літератури, оригінальні дослідження, погляд на проблему, випадок з практики, короткі повідомлення Вона включала: курс препаратів базисної терапії, а саме нестероїдні протизапальні препарати, хондропротектори і/або хондростимулятори, ферментні засоби (панкреатин), а спазмолітики, прокінетики, інгібітори протонної помпи у режимі «за вимогою»; 2-а група (34 пацієнти) отримувала додатково до протокольної схеми пробіотично-вітамінно-мінеральний комплекс Біон 3 по 1 таблетці один раз на добу протягом 6 тижнів.

Результати й обговорення. Вихідні дані у обох групах були зіставними. У таблиці 1 наведено ди-

наміку показників імунного статусу до та після застосування запропонованих схем лікування. Аналіз вхідних даних до лікування показав наявність при ПОА у поєднанні із ХП вторинної імунної недостатності за відносним супресорним варіантом, Т-лімфоцитопенії І-ІІ ст. Одночасно у пацієнтів зростав вміст у сироватці крові всіх класів імуноглобулінів, що свідчило про наявність хронічного торпідного запального процесу. Також встановили зниження неспецифічної резистентності за рівнем активності комплементу.

Таблиця 1. Динаміка показників імунного статусу під впливом запропонованих методик лікування

\begin{tabular}{|c|c|c|c|c|c|}
\hline \multirow{3}{*}{$\begin{array}{c}\text { Показник } \\
\text { імунограми }\end{array}$} & \multicolumn{5}{|c|}{ Група порівняння } \\
\hline & \multirow{2}{*}{$\begin{array}{c}\text { контроль } \\
(\mathrm{n}=30)\end{array}$} & \multicolumn{2}{|c|}{$\begin{array}{c}1 \text { група } \\
(n=33)\end{array}$} & \multicolumn{2}{|c|}{$\begin{array}{c}2 \text { група } \\
(n=34)\end{array}$} \\
\hline & & до лікування & після лікування & до лікування & після лікування \\
\hline CD3, \% & $66,41 \pm 0,61$ & $\begin{array}{c}45,45 \pm 0,74^{*} \\
\mathrm{P}_{2-3}<0,05\end{array}$ & $52,67 \pm 1,25 * *$ & $\begin{array}{c}44,65 \pm 0,74^{* * *} \\
\mathrm{P}_{4-5}<0,05 \\
\end{array}$ & $\begin{array}{c}54,87 \pm 1,12 * * * * \\
\mathrm{P}_{2-5}<0,05\end{array}$ \\
\hline CD22, \% & $14,98 \pm 0,12$ & $\begin{array}{c}20,75 \pm 0,38 * \\
P_{2-3}<0,05\end{array}$ & $18,74 \pm 0,39 * *$ & $\begin{array}{c}20,68 \pm 0,35^{* * *} \\
\mathrm{P}_{4-5}<0,05\end{array}$ & $\begin{array}{c}18,02 \pm 0,37 * * * * \\
\mathrm{P}_{2-5}<0,05\end{array}$ \\
\hline CD16, \% & $13,26 \pm 0,10$ & $\begin{array}{c}10,04 \pm 0,19 * \\
\mathrm{P}_{2-3}<0,05\end{array}$ & $11,76 \pm 0,36 * *$ & $\begin{array}{c}9,96 \pm 0,11 * * * \\
\mathrm{P}_{4-5}<0,05 \\
\end{array}$ & $\begin{array}{c}12,59 \pm 0,21 * * * * \\
\mathrm{P}_{2-5}<0,05\end{array}$ \\
\hline CD4, \% & $39,99 \pm 0,76$ & $\begin{array}{c}30,71 \pm 0,45^{*} \\
\mathrm{P}_{2-3}<0,05\end{array}$ & $35,32 \pm 0,56^{* *}$ & $\begin{array}{c}30,54 \pm 0,53^{* * *} \\
\mathrm{P}_{4-5}<0,05\end{array}$ & $\begin{array}{c}37,75 \pm 0,32 * * * * \\
\mathrm{P}_{2-5}<0,05\end{array}$ \\
\hline CD8, \% & $26,15 \pm 0,65$ & $\begin{array}{c}13,84 \pm 0,34^{*} \\
\mathrm{P}_{2-3}<0,05\end{array}$ & $18,43 \pm 0,49 * *$ & $\begin{array}{c}13,57 \pm 0,32 * * * \\
P_{4-5}<0,05\end{array}$ & $\begin{array}{c}20,13 \pm 0,65 * * * * \\
\mathrm{P}_{2-5}<0,05\end{array}$ \\
\hline $\lg \mathrm{G}$, г/л & $8,42 \pm 0,14$ & $\begin{array}{c}12,27 \pm 0,26 * \\
\mathrm{P}_{2-3}<0,05\end{array}$ & $11,34 \pm 0,23 * *$ & $\begin{array}{c}12,39 \pm 0,17^{* * *} \\
\mathrm{P}_{4-5}<0,05 \\
\end{array}$ & $\begin{array}{c}10,43 \pm 0,14^{* * * *} \\
P_{2-5}<0,05\end{array}$ \\
\hline $\lg$ А, г/л & $1,79 \pm 0,05$ & $\begin{array}{c}2,76 \pm 0,16^{*} \\
\mathrm{P}_{2-3}<0,05\end{array}$ & $2,65 \pm 0,07 * *$ & $\begin{array}{c}2,53 \pm 0,15^{* * *} \\
\mathrm{P}_{4-5}<0,05 \\
\end{array}$ & $\begin{array}{c}2,15 \pm 0,07^{* * * *} \\
\mathrm{P}_{2-5}<0,05 \\
\end{array}$ \\
\hline $\lg M$, г/л & $1,55 \pm 0,01$ & $\begin{array}{c}2,89 \pm 0,17 * \\
\mathrm{P}_{2-3}<0,05\end{array}$ & $\begin{array}{l}2,14 \pm \\
0,05^{* *} \\
\end{array}$ & $\begin{array}{c}2,92 \pm 0,12 * * * \\
\mathrm{P}_{4-5}<0,05\end{array}$ & $\begin{array}{c}1,95 \pm 0,09 * * * * \\
\mathrm{P}_{2-5}<0,05\end{array}$ \\
\hline ЦІК, ум. Од. & $64,75 \pm 0,64$ & $\begin{array}{c}234,45 \pm 7,34^{*} \\
\mathrm{p}_{2-3}<0,05\end{array}$ & $178,92 \pm 4,09 * *$ & $\begin{array}{c}238,37 \pm 6.28^{*} \\
\mathrm{P}_{4-5}<0,05 \\
\end{array}$ & $\begin{array}{c}163,35 \pm 4,28 * * * * \\
\mathrm{P}_{2-5}<0,05\end{array}$ \\
\hline $\begin{array}{l}\text { Комплемент }\left(C_{\mathrm{H} 50}\right) \text {, } \\
\text { гем.од }\end{array}$ & $290,32 \pm 2,05$ & $\begin{array}{c}154,65 \pm 3,65^{*} \\
\mathrm{p}_{2-3}<0,05\end{array}$ & $198,55 \pm 4,47^{* *}$ & $\begin{array}{c}149,54 \pm 3,54 * * * \\
\mathrm{P}_{4-5}<0,05 \\
\end{array}$ & $\begin{array}{c}203,47 \pm 4,65 * * * * \\
\mathrm{P}_{2-5}<0,05\end{array}$ \\
\hline IPI (CD4/CD8) & $1,69 \pm 0,02$ & $\begin{array}{c}2,14 \pm 0,06 * \\
\mathrm{P}_{2-3}<0,05\end{array}$ & $2,04 \pm 0,03 * *$ & $\begin{array}{c}2,12 \pm 0,02 * * * \\
\mathrm{P}_{4-5}<0,05 \\
\end{array}$ & $\begin{array}{c}1,89 \pm 0,03 * * * * \\
\mathrm{P}_{2-5}<0,05\end{array}$ \\
\hline
\end{tabular}

Примітки: $1 . .^{*}-(<0,05)$;

2. ** $-(<0,05)$;

3. ***- $(<0,05)$;

4. $* * * *-\left(P_{1-5}<0,05\right)$.

Дослідження показало, що динаміка параметрів імунного статусу в 2-й групі, пацієнтам якої додатково призначали пробіотично-вітамінно-мінеральний комплекс Біон 3, була більш статистично достовірно значимою, ніж така у 1-й групі $(p<0,05)$. У 2 -й групі пацієнтів рівень CD3 після проведеного лікування зріс на $22,9 \%, \mathrm{CD} 4$ - на $23,6 \%$, CD 8 - на $48,3 \%$, рівень CD 16 - на $26,4 \%$, рівень CD22 знизився на $12,9 \%$, що практично наближалось до вікових норм. У 1-й групі хоча й з'явилася позитивна динаміка (рівень CD3 підви- щився на $15,9 \%$, CD4 - на $15,0 \%$, CD 8 - на $37,2 \%$, рівень CD16 - на $17,1 \%$, рівень CD22 знизився на 9,7 \%), проте після лікування імунологічні показники залишались на рівні Т-лімфоцитопенії I ст. Також статистично значимо знизився рівень усіх досліджуваних класів імуноглобулінів у обох групах: Ig G знизився на 7,6 \% у 1-й групі і на $15,8 \%$-у 2-й групі, Ig M- на 25,9 \% і 33,2 \% відповідно, Ig Aна 5,9 \% і 15,0 \% відповідно. У 2-й групі після лікування регрес вказаних показників був статистично значимо більш вагомим $(p<0,05)$. Рівень актив- 
Огляди літератури, оригінальні дослідження, погляд на проблему, випадок з практики, короткі повідомлення ності комплементу зріс у обох досліджуваних групах після лікування (на 28,4 \% у 1-й групі і на 36,1 \% - у 2-й групі), що свідчить про активацію неспецифічних факторів захисту імунної системи після лікування, проте лікувальний ефект у 2-й групі був вагомішим. Також статистично значимо знизився рівень ЦІК після лікування - у 1-й групі на 23,7 \%, у 2-й групі - на 31,5\%.

Отримані дані динаміки параметрів імунної системи довели вищу ефективність комплексної терапії із включенням курсу пробіотично-вітамінно-мінерального комплексу Біон 3, що дозволяє рекомендувати його до практичного використання у пацієнтів з первинним остеоартрозом на тлі функціональної недостатності ПЗ панкреатогенного характеру.

Висновки 1. У хворих на ПОА у поєднанні із ХП виявили наявність вторинної імунної недостатності за відносним супресорним варіантом, Т-лімфоцитопенію I-II ст., активацію гуморальної ланки імунітету за рівнями імуноглобулінів, а також зниження неспецифічної резистентності за рівнем активності комплементу.

2. Встановили, що використання у комплексному лікуванні хворих на ПОА у поєднанні із ХП пробіотично-вітамінно-мінерального комплексу Біон 3 за схемою по 1 таблетці один раз на добу протягом 6 тижнів сприяє нормалізації показників імунного статусу $(p<0,05)$.

У перспективі подальших досліджень плануємо вивчити вплив вказаного терапевтичного комплексу на параметри трофологічного статусу.

\section{ЛІТЕРАТУРА}

1. Babinets L. S. The trophological status of patients with osteoarthrosis and excretory insufficiency of pancreas / L. S. Babinets, I. M. Halabitska // Health of Society. 2019. - No. 8 (2). - P. 41-44.

2. Osteoarthritis / Glyn-Jones S. Palmer, A. J. R. Agricola, R. Price [et al.] // The Lancet. -2015. -No. 386 (9991). P. 376-387.

\section{REFERENCES}

1. Babinets, L.S., \& Halabitska, I.M. (2019). The trophological status of patients with osteoarthrosis and excretory insufficiency of pancreas. Health of Society, 8 (2), 41-44.

2. Glyn-Jones, S., Palmer, A.J.R., Agricola, R., Price, A.J., Vincent, T.L., Weinans, H., \& Carr, A.J. (2015). Osteoarthritis.

The Lancet, 386 (9991), 376-387.

3. Pendharkar, S.A., Salt, K., Plank, L.D., Windsor, J.A., \& Petrov, M.S. (2014). Quality of life after acute pancreatitis a systematic review and meta-analysis. Pancreas, 43 (8), 1194-1200.

\section{ВЛИЯНИЕ ПРОБИОТИЧЕСКО-ВИТАМИННО-МИНЕРАЛЬНОГО КОМПЛЕКСА НА ИММУНОЛОГИЧЕСКИЕ ПАРАМЕТРЫ ПРИ ОСТЕОАРТРОЗЕ НА ФОНЕ ЭКСКРЕТОРНОЙ ГИПОФУНКЦИИ ПОДЖЕЛУДОЧНОЙ ЖЕЛЕЗЫ}

\section{ФЛ. С. Бабинец, И. М. Галабицькая}

Тернопольский национальный медицинский университет имени И. Я. Горбачевского МОЗ Украины

РЕЗЮМЕ. При сочетании первичного остеартроза и панкреатогенной экскреторной недостаточности поджелудочной железы у пациентов развиваются изменения иммунологического статуса.

Цель - усовершенствовать известный способ лечения путем дополнительного назначения пациентам с первичным остеартрозом в сочетании с панкреатогенной экзокринной недостаточностью поджелудочной железы пробиотическо-витаминно-минерального комплекса, направленного на коррекцию нарушений в иммунном статусе.

Материал и методы. Обследовано 67 пациентов с первичным остеоартрозом в сочетании с панкреатогенной экзокринной недостаточностью поджелудочной железы. Иммуный статус пациентов оценивали по уровням CD3, CD22, CD4 и CD8, CD16, Ig M, G, A и активности комплемента. Пациенты были поделены на две группы: первая группа получала протокольное лечение, вторая группа дополнительно к протокольному лечению получала пробиотическо-витаминно-минеральный комплекс. 
Огляди літератури, оригінальні дослідження, погляд на проблему, випадок з практики, короткі повідомлення

Результаты. У исследуемых пациентов выявлено наличие вторичной иммунной недостаточности по относительному супрессорному варианту на фоне роста уровней всех исследуемых классов иммуноглобулинов, а также снижение неспецифической резистентности по уровню активности комплемента. После комплексного лечения иммунологический статус пациентов статистически значимо улучшился в обеих группах, однако во 2-й группе лечебный эффект оказался более весомым.

Вывод. Использование в комплексном лечении больных первичным остеоартрозом в сочетании с панкреатогенной экзокринной недостаточностью поджелудочной железы пробиотическо-витаминно-минерального комплекса Бион 3 по схеме по 1 таблетке один раз в сутки в течение 6 недель способствует нормализации показателей иммунного статуса $(p<0,05)$.

КЛЮчЕВЫЕ СЛОВА: первичный остеоартроз; экскреторная недостаточность поджелудочной железы; иммунный статус; пробиотическо-витаминно-минеральный комплекс.

\section{INFLUENCE OF PROBIOTIC-VITAMIN-MINERAL COMPLEX ON IMMUNOLOGICAL PARAMETERS AT OSTEOARTHRITIS AND EXCRETORY HYPOFUNCTION OF PANCREAS}

\section{○L. S. Babinets, I. M. Halabitska}

\section{Horbachevsky Ternopil National Medical University}

SUMMARY. Changes of the immunological status develop in patients at a combination of primary osteoarthritis and pancreatogenic excretory insufficiency of a pancreas.

The aim of the study - to improve the known method of treatment by additional administration to patients with primary osteoarthritis in combination with pancreatogenic exocrine insufficiency of the pancreas probiotic-vitaminmineral complex aimed at correcting disorders in the immune status.

Material and Methods. 67 patients with primary osteoarthritis in combination with pancreatogenic exocrine pancreatic insufficiency were examined. Patients' immune status was assessed by levels of CD3, CD22, CD4 and CD8, CD16, I $M, G, A$ and complement activity. Patients were divided into two groups: group 1 received protocol treatment, group 2 in addition to protocol treatment received a probiotic-vitamin-mineral complex.

Results and Discussion. The studied patients revealed the presence of secondary immune deficiency in the relative suppressor variant against the background of increasing levels of all studied classes of immunoglobulins, as well as a decrease in nonspecific resistance in the level of complement activity. After comprehensive treatment, the immunological status of patients improved statistically significantly in both groups, but in group 2 the therapeutic effect was more significant.

Conclusion. It was found that the use in the complex treatment of patients with primary osteoarthritis in combination with pancreatogenic exocrine insufficiency of the pancreas probiotic-vitamin-mineral complex Bion 3 according to the scheme of 1 tablet once a day for 6 weeks contributes to the normalization of immune status.

KEY WORDS: primary osteoarthritis; excretory insufficiency of the pancreas; immune status; probiotic-vitaminmineral complex. 